\title{
Challenges and Achievements of Microcredit in Bangladesh: A Case Study
}

Md. Aminul Islam ${ }^{1 *}$, Md. Mohshin Khan ${ }^{2}$, Md. Dulal Hossain ${ }^{3}$

${ }^{1}$ Senior Officer (Audit), AVA development Society, Natore, Bangladesh

${ }^{2}$ Lecturer, Dept. of Accounting, Raipur Residential College, Lakshmipur, Bangladesh

${ }^{3}$ Senior Officer (Microcredit), SAJIDA Foundation, Munshiganj, Bangladesh

DOI: $10.36347 /$ sjebm.2020.v07i09.009

| Received: 09.08.2020 | Accepted: 26.08.2020 | Published: 30.09 .2020

*Corresponding author: Md. Aminul Islam

Abstract

Review Article

Microcredit programs (MCP) in Bangladesh are implemented by various formal financial institutions (nationalized commercial banks and specialized banks), specialized government organizations and semi-formal financial institutions (nearly 700 NGO -MFIs). The growth in the MFI sector, in terms of the number of MFI as well as total membership, was phenomenal during the 1990s and continues till today. The total coverage of MCP in Bangladesh is approximately 13 million households. The coverage of major institutions in the formal and semi-formal sectors. There is debate, however, on the extent of overlap- one borrower taking loan from more than one microfinance institution. The general consensus is that a national average would be that $15 \%$ of all borrowers are borrowing from more than one MFI. In that case the effective coverage is about 11 million households. Out of 11 million households covered by MCP, about $80 \%$ are below poverty line and so about 8.8 million poor households are covered by MCP. With an estimated households of 26 million, out of which about $46 \%$ are poor households, the total number of poor households is approximately 11.96 million. Therefore, there is still scope of extending the coverage of microcredit programs to an approximate 3.16 million households. Bangladesh government has also placed adequate emphasis on microcredit programs. The Interim Poverty Reduction Strategy Paper (IPRSP) of the government of Bangladesh has outlined some important roles for microcredit. The policy makers have recognized the importance of microcredit in Bangladesh and the present government has pledged its support to this program. Recognizing the importance of microcredit in poverty alleviation, the major challenge now, the UN has declared 2005 as the UN International Year of Microcredit. With combined efforts of the governments, MFIs, donor agencies and above all the peoples of the nations through a multipronged approach poverty will be removed from the face of the earth and thus peace in its true sense will be restored around the world.

Keywords: Microcredit, MFI, MCP, poverty.

Copyright @ 2020: This is an open-access article distributed under the terms of the Creative Commons Attribution license which permits unrestricted use, distribution, and reproduction in any medium for non-commercial use (NonCommercial, or CC-BY-NC) provided the original author and source are credited.

\section{INTRODUCTION}

In recent years, microcredit, in its wider dimension known as microfinance, has become a much favoured intervention for poverty alleviation in the developing countries and least development countries. There is scarcely a poor country and development oriented donor agency (multilateral, bilateral and private) not involved in the promotion (in one form or other) of a microfinance program [1, 2]. Many achievements are claimed about the impact of microfinance programs, and an outside observer cannot but wonder at the range of diversity of the benefits claimed. Although Bangladesh has huge potential for development, it is, for various socio-economic reasons, among the poorest countries in the world. About half of the country's population live below the poverty line with $80 \%$ in the rural areas. The burden of poverty falls disproportionately on women, who constitute half of the total population. Logically, therefore, poverty alleviation and creation of rural employment are top priorities in the development agenda of the government of Bangladesh (GOB) which has adopted a broad-based approach to poverty alleviation, emphasizing macroeconomic stability, economic liberalization, and support for a number of government agencies and nongovernment organizations (NGOs). Substantial progress has been made in implementing the microcredit program (MCP), and the scope for its efficient expansion is enormous. Money begets money. Adam Smith said "Money, says the proverb, makes money [3, 4]. When you have got a little, it is often easy to get more. The great difficulty is to get that little" ("The Wealth of Nations" 1937, p. 93). It is very difficult for 
the poor to get small working capital from formal banking system for various reasons. A collateral free working capital loan is the requirement at the door steps of the poor at the right time to help them facilitate and start feasible intended income generating activities (IGAs). It is with this background that, microfinance is seen as one of the significant approaches to poverty alleviation [5-8].

\section{Evolution of Microfinance Institutions in Bangladesh}

During the late 1970s, when the 'Jobra' experiment was underway under Professor M. Yunus, the Dheki Rin Prokolpa was initiated by the Bangladesh Bank in collaboration with the Swanirvar Bangladesh, and several other pilot schemes were initiated by a handful of the NGOs which were active then [9]. At that time, it was difficult to conceive that these initiatives would lead to a major microcredit movement, which would make Bangladesh known to the rest of the world. Even during the 1980s, in spite of Grameen Bank's success, the main discourse amongst development practitioners in Bangladesh centered on the desirability of microcredit program as opposed to conscientization. By 1990, unhindered experimentation in the fields led to a quiet resolution of the debate and the country experienced a massive expansion of microfinance activities during the 1990s. PKSF contributed significantly to the expansion of microcredit programs in Bangladesh $[10,11]$.

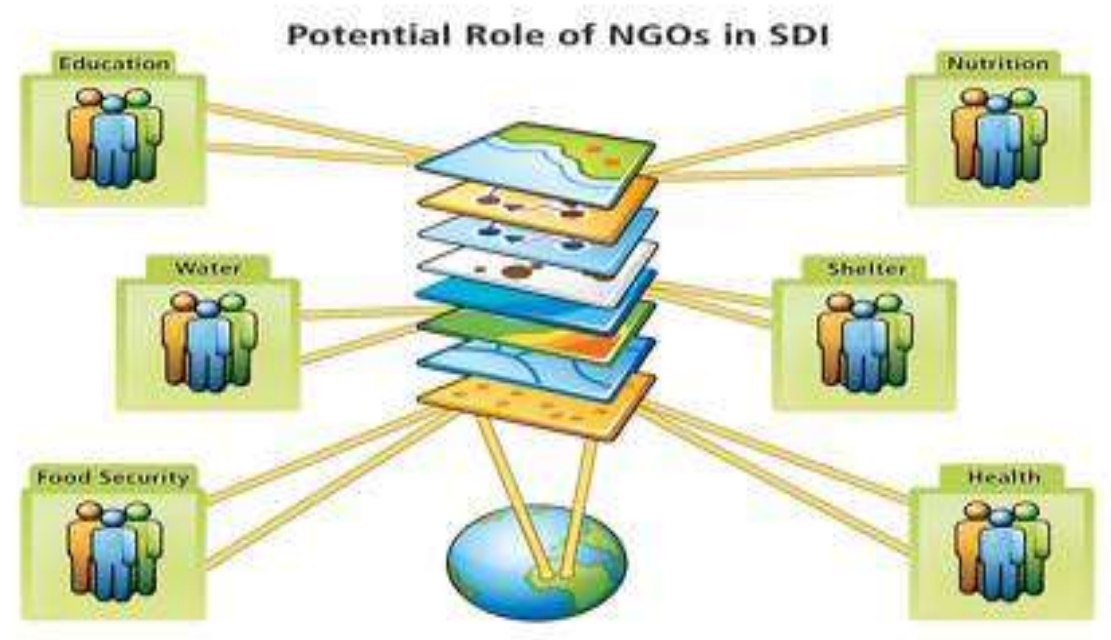

Fig-1: Contribution of NGO's in Development of Bangladesh Economy

\section{Case Study}

This is borne out by the figures on the time path of NGO-microfinance institutions (NGO-MFIs) expansion (see Figure-1), as well as, by the expansion in membership in these MFIs (see Figure-2). This rapid expansion drew attention from all important quarterspolicymakers, academia and development practitionerseach trying to grapple with the unfolding stream of issues and trying to shape the course of the social and economic dynamics initiated due to introduction of microcredit. With a view to meet the demand for fund for re-lending by the development partners (NGO MFIs), and due to an urge to coordinate the flow of such funds to appropriate use, the Palli Karma-Sahayak Foundation (acronym PKSF and the full Bengali name can be translated in English as "Rural Employment Support Foundation") came into being in late 1990. Over the years, its share in the revolving loan fund of the MFIs increased- from 9 percent in 1996 to 24 percent in 2002. In recent years MFIs have moved from the margins of the financial system towards the mainstream. It is now more widely accepted that populations traditionally excluded by the formal financial sector can, in fact, be a profitable market niche for innovative banking services. The 1997 Microcredit
Summit held in Washington D.C., launched a global movement to reach 100 million of the world's poorest families with credit for self-employment and other financial and business services by the year 2005. Much remains to be done, however, to integrate microfinancial systems, and for orthodox financial institutions, notably commercial banks, to recognize its full potential. Microcredit programs (MCP) in Bangladesh are implemented by various formal financial institutions (nationalized commercial banks and specialized banks), specialized government organizations and semi-formal financial institutions (nearly 700 NGO -MFIs). The growth in the MFI sector, in terms of the number of MFI as well as total membership, was phenomenal during the 1990s and continues till today. The total coverage of MCP in Bangladesh is approximately 13 million households. The coverage of major institutions in the formal and semi-formal sectors. There is debate, however, on the extent of overlap- one borrower taking loan from more than one microfinance institution. The general consensus is that a national average would be that $15 \%$ of all borrowers are borrowing from more than one MFI. In that case the effective coverage is about 11 million households. Out of 11 million households 
covered by MCP, about $80 \%$ are below poverty line and so about 8.8 million poor households are covered by MCP. With an estimated households of 26 million, out of which about $46 \%$ are poor households, the total number of poor households is approximately 11.96 million. Therefore, there is still scope of extending the coverage of microcredit programs to an approximate 3.16 million households. PKSF currently provides loanable funds to 195 POs- 3 big and 192 small and medium- under its four mainstream credit programs: Rural Microcredit; Urban Microcredit; Microenterprise credit and Microcredit for the Hardcore Poor. It charges differential service charges for its two categories of POs: $7 \%$ for the big POs and $4.5 \%$ for the small and medium POs. It also operates a loan program for capacity enhancement of POs at a subsidized rate of $1 \%$ service. It provides customized training courses and has a well-developed training strategy including outsourcing to private and public sector institutes. Onsite technical assistance is also offered during the intensive schedule of field visits undertake $n$ by PKSF personnel. Upto June 2004, PKSF has disbursed a total amount of about US\$ 313.08 million among 5.10 million poor borrowers about $90 \%$ of whom are women. PKSF's loan recovery rate is over $98 \%$. Independent evaluation studies have shown that PKSF's microcredit program implemented through its POs has helped alleviation of poverty.

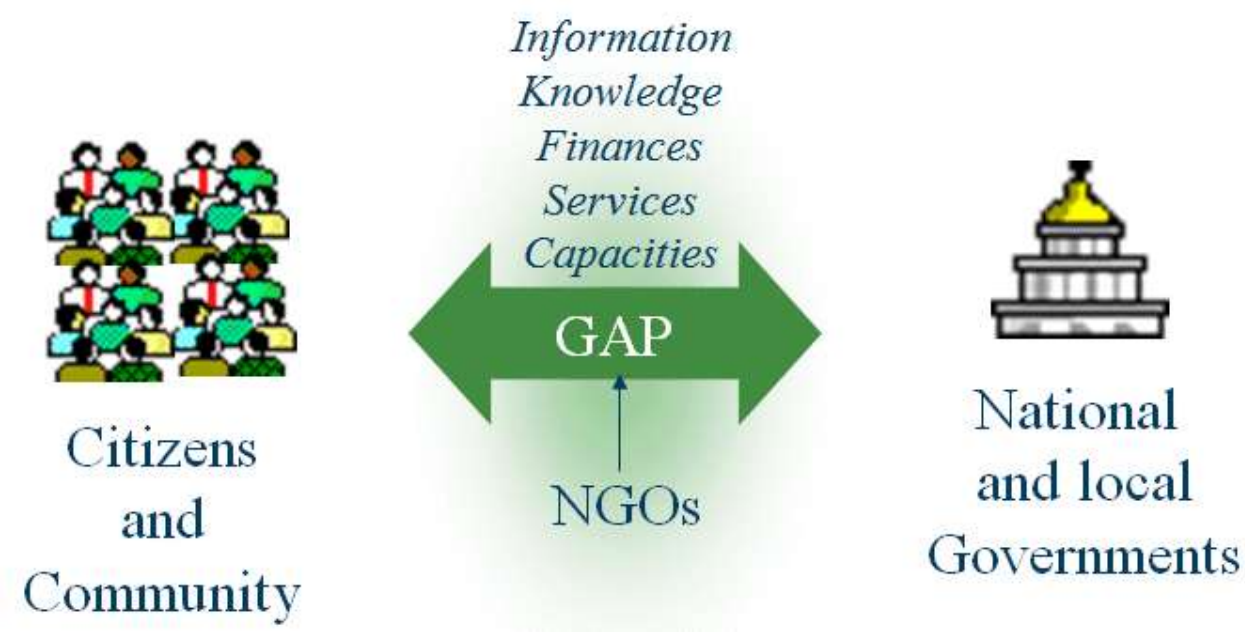

Fig-2: Resources required by the NGO Sector

\section{DISCUSSION}

\section{Findings of Study by BIDS}

Palli Karma-Sahayak Foundation (PKSF) commissioned a survey (1997-2001) through the Bangladesh Institute of Development Studies (BIDS) covering 3026 sample households from 91 villages under 13 POs of PKSF. A census was administered in late 1997, covering 19151 households in 91 villages. Some of the major findings are given below:

\section{Economic Impacts of Microfinance (a) Income}

The 1998 survey found the average annual income of participant households to be higher than that of the non-participants. Self-employment activities had more than $50 \%$ contribution to total income for the participants as against 43 percent in case of nonparticipants. The second BIDS survey suggests that nominal household income increased by 19 percent in program villages and by only 13.5 percent in control villages. Compared to non-participants the participant households were better able to cope with flood, sustain their income, and achieve higher purchasing power and consumption level.

\section{(b) Food Security}

The BIDS study finds the program participants, due to greater access to sharecropping, had better food security and about 26 percent of rice consumption out of own production (after sale), which was also marginally higher than the non-participants.

\section{(c) Wage}

Wage earning contributed about 23 percent of total annual income for the land-poor households. Microcredit helped participant households to earn about 8 percent higher income than that of the non-participants.

\section{(d) Employment}

The participant households are better able to ensure more employment on own farms due to their better access to the land rental market. Wage and selfemployment in non-agricultural sector is also higher for the participant households due to their access to microcredit program.

\section{(e) Assets: land and non-land}

Average size of land owned by participant households is lower than the non-participants; 91 decimals compared to 149 decimals. The BIDS study however suggests that the eligible participant's mortgage or rent-in more land than the non-participants, and 
therefore, have larger operational holding. Higher percentage of program participants own poultry, goat/sheep and cows compared to non-participants. A higher percentage of the participants own bicycles $(12.5 \%$ compared to $8 \%)$, boat $(3.7 \%$ compared to $1.6 \%)$, irrigation equipment $(1.23 \%$ compared to $0.23 \%)$, radio (17.9\% compared to $12.6 \%)$ and rickshaw/van $(8 \%$ compared to $2 \%$ ) thus showing higher asset ownership of the participants.

\section{Social and Other Development Impacts: (a) Health and Nutrition:}

There is positive program placement effect on nutrition status.

\section{(b) Sanitation and Drinking Water:}

The BIDS study finds small positive influence of participation on waste disposal and use of sanitary toilets among the land-poor households with no clear evidence of program impact on hand-washing. The use of pure drinking water from hand tublewell was found universal.

\section{(c) Literacy and School Enrollment of Children:}

Adult literacy rate is significantly higher among the eligible participants. The BIDS study also found that program participation increases the chance of both boys and girls to be enrolled in schools.

\section{(d) Empowering Women:}

Microcredit programs' main target is women. There are strong evidences that, microcredit programs contribute to women's empowerment. One consistent finding is the increased self-confidence and increased self-esteem. Another is women's increased in decision making in the areas of family planning, children's marriage, buying and selling of properties and sending daughters to school. There have been some evidences that members of microfinance institutions are able to stop domestic violence due to personal empowerment and through group action. In Bangladesh, microcredit programs have also increased women's participation in the activities of local government. Some women microcredit clients have been elected as Chairpersons and Members of various Union Parishads, the lowest and most vibrant tier of local government. Now women microcredit clients take greater roles in community activities and organizing for social change.

\section{Major Issues}

\section{Targeting the Poorest Versus Achieving Financial} Sustainability: The Dilemma in Microcredit

Studies of microcredit programs show that these have been successful in improving the economic condition of the members. Macro studies, however, show that there has not been any significant decline in the overall levels of poverty. This apparent contradiction may be partially due to the fact that the microcredit programs have not been very successful in including the hard core poor, who constitute about half of the poor in Bangladesh. The poorest may have been left out because quite often the destitute themselves feel they are not credit worthy and the microcredit programs also do not judge them to have the entrepreneurial ability necessary to handle money properly. Perhaps microcredit, especially in the form that is currently in practice, is not the answer for the hard core poor. Normally, the MFIs have been successful in expanding their outreach by providing microcredit to increasing numbers of borrowers who are near the poverty line, not well below that. The MFIs adopt this approach to reach financial viability within a reasonable time frame. If the MFIs are to borrow (from PKSF and other sources) at a rate close to market rate of interest, the effort to reach financial viability may become difficult and delayed. The partner organizations (POs) of PKSF have achieved financial viability at the present (subsidized) rate of service charge of PKSF. Therefore, in the context of Bangladesh there seems to be a trade -off between outreach and sustainability of MFIs and they should strike a judicious balance between the two which may enable them to achieve financial sustainability. Experiences suggest that the financial needs of the poor are best served by encouraging a broad range of institutions to provide efficient and responsive lending, savings, insurance, and other financial services that poor people need to build their business, increase income and assets, and reduce risks. Poor people need sustained access to an evolving set of financial products and services. These can only be provided by financially sustainable institutions, dealing with diverse segments and products, each in the position to increase outreach and grow with their clients.

\section{Widening the Target Group: New Products and New financial Technologies}

The MFIs have some scope to expand horizontally-devising ways to include more people from the target group. More important is, as older borrowers graduate to higher income brackets, new products need to be devised to meet their changing needs. These new products may also help the MFIs to expand vertically by tapping borrowers outside the target group. A possible way to expand horizontally is to include more men. Research in Bangladesh and elsewhere show that men usually borrow larger amount. However, their repayment record is not as good as women. Including more men will allow MFIs to attain sustainability quickly, but it will also mean that the repayment performance of an institution will suffer as well. As the microcredit movement matures it faces the varied requirements of the borrowers and the need to offer a larger package of products.

\section{Accessing Non-Donor Source of Financing}

It is fair to say that donor funding and enthusiasm for microcredit will diminish in the future. This means that MFIs have to look for new avenues to fund their activities, potential source of fund will be to 
mobilize saving deposits of members and nonmembers. Another alternative is to try to tap commercial source of funding such as commercial banks, the local stock market and financial market. This option might be open only to large and well-established MFIs and may not be feasible for small MFIs.

\section{Internal and External Governance Issues}

Research in Bangladesh and other places show that a crucial element for the success of a credit granting NGO-MFI is the quality of leadership and management. The governance of NGOs is increasingly being discussed nowadays. Research findings indicate that governance and financial sustainability are closely interrelated. Weak governance and management characterize many microfinance NGOs in Bangladesh. It is commonplace to find friends, close relatives, retired bureaucrats, and such other persons in the governing bodies. They are mere onlookers and remain uninvolved with the board's business. The chief executives are said to overpower the boards. If this is the situation, good governance will not occur by just inducting good people in the governing body. The essence of governance is to ensure an overall system of structuring accountability and transparency in an organization. The problems of governance are mostly due to the inadequacy of the existing laws and regulations and lack of reporting, supervision and monitoring. The MFIs are not to blame fully for this.

\section{Sustainability of Microcredit Borrowers}

An individual member may be considered as sustainable when he/she is capable of meeting the basic needs of his/her family without borrowing money/capital from the project or any other sources like banks etc. for consumption purposes. However, loans can be taken for IGAs. Most people are of the opinion that a member's sustainability should be judged by two separate but inter -dependent criteria, viz, (i) social development and (ii) economic development. Controversies, however, exit as to which of the two criteria should go first. Some people argue that economic development is a pre-condition for social development while some others consider social development as a prerequisite for economic development. Most people, however, are of the opinion that the two interactive and therefore be pursued simultaneously. Sustainability of borrowers is also linked with some programme challenges of MFIs, like devising appropriate microinsurance schemes and social protection schemes, providing other financial services to the poor.

\section{Service Charge of MFIs}

The MFIs in Bangladesh usually charge flat rate of 12 to $15 \%$ per annum from the microcredit borrowers. The effective rate becomes about 20 to $28 \%$ at the borrowers' level. Recently, there has debate whether this rate is too high or not. The critics of service charges of MFIs compare, somewhat erroneously, with interest rates of the conventional formal banking system. Microcredit is "banking at the doorstep" of the poor borrowers. The monitoring and supervision are quite intensive and costly. Therefore, the comparison with formal banks is not proper. There are several other factors like risks associated with collateral free loan, provisioning for doubtful and bad loans, compulsion to build up MFI's equity and attaining financial sustainability also are determinants of service charge of microcredit programs, Bangladesh microcredit sector has relatively lower rate of service charge compared to many other countries. However, social obligations, political realities and credit at a competitive rate may require consideration of reducing the rate by MFIs. But that should not be done by resorting to capping the rate. The actions to increase efficiency in the credit operation of MFIs, information flow at grassroots level regarding charges of various MFIs, increasing the loan size for the borrowers and healthy competition among MFIs may lead to competitive rates acceptable to all concerned.

\section{Regulatory Framework}

This issues has come to the forefront because MFIs are providing financial services and products to the poor, outside the formal banking system. In view of the history of MFIs (most of which are NGOs), it can be argued that the conventional regulatory framework such as that of formal banks and financial institutions is not appropriate and hence not required under the circumstances prevailing in many countries. This is particularly in view of the fact that many MFIs are not accepting deposits with checking facilities. The unique features of MFIs in the field of social and financial services with the core objectives of poverty alleviation differentiate the industry from the formal financial sector and further justify this proposition. However, that does not in any way downplay the importance of having some strategic monitoring measures that are compatible and appropriate to MFIs' objectives, institutional operation and develo pment culture. The measures should incorporate user-friendly prudential norms/indicative guidelines in the form of a concrete 'Code of Norms/Conduct' which would ensure sound and organized growth of MFIs on a sustainable basis.

A set of financial standards, reporting formats and performance standards may be an effective way to keep the MFIs on the right track. There is a broad range of experiences to draw from in establishing appropriate standards, including the work being done by PKSF in Bangladesh (See Box). An independent autonomous apex body outside the government's control is the best option to ensure that the 'code of conduct' and the microcredit standards are complied with by the MFIs. Non-compliance by the MFIs may ultimately result in canceling the permission/registration of a defaulting MFI. The government has recently decided to give the responsibility to devise a regulatory framework to a Committee headed by the Governor of the central bank 
of Bangladesh. The Committee has already formulated a set of reporting formats to be followed by MFIs and also drafting a law for microcredit programs in Bangladesh.

\section{CONCLUSION}

Microcredit, originated in Bangladesh has spread all over the globe. Today within the global coverage of microcredit Bangladesh's achievement stands out prominently. According to the Microcredit Summit Campaign Report, 67.6 million families have been reached by microcredit in 2002 around the world. Out of that 59.6 million clients are in Asia and Bangladesh alone covered 13 million clients (22.6\%). The world community has appreciated the contributions of Bangladesh in the field of microcredit, which was evident in the recently held Asia Pacific Region Microcredit Summit (APRMS) Meeting of Councils in Dhaka, Bangladesh from 16-19th February, 2004 arranged by Palli Karma-Sahayak Foundation (PKSF), in association with the Microcredit Summit Campaign based in Washington D.C. More than 1200 participants from 47 countries from different parts of the globe pledged their firm commitment to take forward the microcredit movement. Bangladesh government has also placed adequate emphasis on microcredit programs. The Interim Poverty Reduction Strategy Paper (IPRSP) of the government of Bangladesh has outlined some important roles for microcredit. The policy makers have recognized the importance of microcredit in Bangladesh and the present government has pledged its support to this program. Recognizing the importance of microcredit in poverty alleviation, the major challenge now, the UN has declared 2005 as the UN International Year of Microcredit. With combined efforts of the governments, MFIs, donor agencies and above all the peoples of the nations through a multipronged approach poverty will be removed from the face of the earth and thus peace in its true sense will be restored around the world.

\section{REFERENCES}

1. Ahmed S. Microcredit and Poverty New Realities and Issues, Journal of Bangladesh Studies, USA. 2003.

2. Ahmed S, Hakim MA (Ed.). Attacking Poverty with Microcredit", Palli Karma -Sahayak Foundation (PKSF)/the University Press Ltd. (UPL), Dhaka. 2004.

3. Bangladesh Institute of Development Studies (BIDS). Final Report on BIDS Study on PKSF's Monitoring and Evaluation System (MES), October, Dhaka. 2001.

4. Credit and Development Forum (CDF), "Microfinance Statistics, Various Volumes", Dhaka.

5. Grameen Bank, "Annual Reports of Various Years", Dhaka.

6. Khandker S. Fighting Poverty with MicrocreditExperiences in Bangladesh", The University Press Ltd. (UPL), Dhaka. 1998.

7. Microcredit Summit Campaign, 2003; "State of the Microcredit Summit Campaign Report 2003", Washington D.C.

8. Ministry of Finance, "Bangladesh Economic Review", Various Years, Dhaka. https://mof.portal.gov.bd/site/page/28ba57f5-59ff4426-970a-bf014242179e/Bangladesh-EconomicReview.

9. Palli Karma-Sahayak Foundation (PKSF), "Annual Reports of Various Year's", Dhaka.

10. Palli Karma -Sahayak Foundation (PKSF), 2003; "Report of the International Seminar on Attacking Poverty with Microcredit", Dhaka. DOI: 10.1596/1813-9450-2945

11. Smith A. An Inquiry into the Nature and Causes of the Wealth of Nations, Edwin Cannan (Ed.), the Modern Library/Radom House Inc., New York. 1937. https://www.worldcat.org/title/inquiry-intothe-nature-and-causes-of-the-wealth-ofnations/oclc/167332. 